\title{
Expression of Vimentin, Desmin, CD34 and S100 in Malignant Soft Tissue Tumours in a Study Conducted in Central India
}

\author{
Ravi Kumar Meena ${ }^{1}$, Ashish Koshti², R.K. Nigam³ ${ }^{3}$ Reeni Malik ${ }^{4}$ Abhinav Junwal ${ }^{5}$ \\ 1,2,3,4,5 Department of Pathology, Gandhi Medical College, Bhopal, Madhya Pradesh, India.
}

\section{ABSTRACT}

\section{BACKGROUND}

Soft tissue is mesenchymal in origin and can be defined as non-epithelial extraskeletal tissue of the body exclusive of the reticuloendothelial system, glia, and supporting tissue of various parenchymal organs. In recent times, immunohistochemistry has become an important tool to help the surgical pathologist in many clinically critical scenarios. Immunohistochemistry is an adjunctive diagnostic technique to traditional morphologic methods in soft tissue pathology, as in any other area of surgical pathology.

\section{METHODS}

This study included specimens received for histopathological evaluation in the Department of Pathology, Gandhi Medical College, Bhopal, over a period of one and half years. 50 morphologically proven malignant cases were taken for immunohistochemistry.

\section{RESULTS}

Vimentin was showing immunopositivity in 43 out of 50 cases of MSTT (Malignant Soft Tissue Tumours). 7 cases were reported negative for vimentin including 4 cases of EWS, 2 cases of SS and 1 case each of MFH (Malignant Fibrous Histiocytoma) and liposarcoma. All 5 cases of rhabdomyosarcomas and 2 cases of leiomyosarcomas were showing positivity for Desmin. All other tumours were negative for Desmin. All cases of fibroblastic tumours and GIST (Gastro Intestinal Stromal Tumour) were showing positive results for CD 34 along with 2 cases of MFH, 1 case of LMS (Leiomyosarcoma), 2 cases of MPNST (Malignant Peripheral Nerve Sheath Tumours), 1 case of SRBCT (Small Round Blue Cell Tumour) and 1 case of undifferentiated tumour. All 3 cases of MPNST, both the cases of LMS and the only case of liposarcoma were showing immunopositivity for S 100.5 out of 8 cases of MFH, 2 out of 5 cases of RMS and 1 out of 5 cases of GIST were also showing positivity for S 100. All 7 cases of fibroblastic tumours were negative for $\mathrm{S} 100$.

\section{CONCLUSIONS}

Soft tissue tumours are a large, heterogeneous group of neoplasms. Malignant cases account for less than $1 \%$ of overall human malignant tumours but they are aggressive and may result in a significant diagnostic and therapeutic challenges. Hence, the present study was undertaken to diagnose malignant soft tissue tumours by using immunohistochemistry along with histopathology.

\section{KEY WORDS}

Malignant Soft Tissue Tumours, Immunohistochemistry, Vimentin, Desmin, CD34, S100
Corresponding Author:

Dr. Ashish Koshti,

Department of Pathology,

H.No. 41, Civitech City, Globus Housing,

Nayapura, Lalghati, Bhopal, Madhya

Pradesh, India.

E-mail: drashishpath@gmail.com

\section{DOI: 10.14260/jemds/2020/869}

How to Cite This Article:

Meena RK, Koshti A, Nigam RK, et al. Expression of vimentin, desmin, CD34 and S100 in malignant soft tissue tumours in a study conducted in central India. J Evolution Med Dent Sci 2020;9(52):39773981, DOI: 10.14260/jemds/2020/869

Submission 27-07-2020,

Peer Review 01-11-2020,

Acceptance 09-11-2020,

Published 28-12-2020.

Copyright (C) 2020 Ravi Kumar Meena et al. This is an open access article distributed under Creative Commons Attribution License [Attribution 4.0 International (CC BY 4.0)] 


\section{BACKGROUND}

Soft tissue tumours originate from mesenchymal tissue i.e., adipose tissue, smooth and skeletal muscle, fibrous tissue, endothelium and peripheral nerves etc.; most of them are benign. They exhibit different characteristic histological features, so most of the time diagnosed by morphology alone. But the undifferentiated ones are causing difficulties in diagnosis by histopathology alone. Benign tumours, resemble normal tissue, with a limited capacity for autonomous growth. They have little tendency to invade locally and are attended by a low rate of local recurrence following conservative therapy. Malignant ones, or sarcomas, in contrast, are highly aggressive and are capable of invasion or destructive growth, recurrence, and distant metastasis. Radical surgery is required to ensure the total removal of these tumours. The term sarcoma does not indicate the likelihood or rapidity of metastasis. It has been noticed some sarcomas, such as dermatofibrosarcoma protuberans, rarely metastasize, whereas others do so with alacrity. That's why, it is important to qualify the term sarcoma with the degree of differentiation or the histologic grade. "Well differentiated" and "poorly differentiated" terms used to indicate the relative maturity of the tumor with respect to normal adult tissue. Histologic grade is a means of quantitating the degree of differentiation by using a set of histologic criteria. Often, well-differentiated sarcomas are low-grade lesions, on the other hand poorly differentiated sarcomas are high-grade neoplasms. Tumours of borderline malignancy are characterized by frequent recurrence but rarely metastasis. As with other malignant neoplasms, the pathogenesis of most soft tissue tumours is still unknown. Recognized causes include various physical and chemical factors, exposure to ionizing radiation, and inherited or acquired immunologic defects. An evaluation of the exact cause is often difficult because of the long latent period between the time of exposure and the development of sarcoma, as well as the possible effect of multiple environmental and hereditary factors during the induction period. The origin of sarcomas from benign soft tissue tumours is exceedingly rare, except for malignant peripheral nerve sheath tumours arising in neurofibromas, which are nearly always in patients with the manifestations of type 1 neurofibromatosis (von Recklinghausen disease).

Immunohistochemistry and cytogenetics are newer techniques that helps in making diagnosis of undifferentiated cases. As different tissue of origin exhibits particular immunohistochemical markers, so by using immunohistochemistry we can reach to the diagnosis of undifferentiated cases. Pathologists should know about the nature of immunohistochemical marker expression and the pitfalls that can be introduced by technical factors, such as tissue processing and fixation as well as the immunohistochemistry (IHC) procedures. It is estimated that IHC in fact adds confusion to the diagnostic process in $5 \%$ to $10 \%$ of cases. $^{1}$

Increased use of immunohistochemistry and cytogenetics result in significant changes have been made regarding the diagnosis and classification of Soft Tissue Sarcoma (STS). Many new entities have been recognized of which desmoplastic small round cell tumour and intimal sarcomas are examples. ${ }^{2}$ Vimentin, a $57-\mathrm{kDa}$ intermediate filament protein, is expressed in all mesenchymal cells. Vimentin is ubiquitously expressed in all cells during early embryogenesis and is gradually replaced in many cells by type-specific intermediate filaments. Vimentin is expressed in virtually all mesenchymal tumours and is therefore of minimal value in identifying particular tumours. Desmin is the intermediate filament protein associated with both smooth and skeletal muscle differentiation; it is rarely expressed by myofibroblasts and their corresponding tumours. In skeletal muscle, desmin is localized to the Z-zone between the myofibrils, where it presumably serves as binding material for the contractile apparatus. The S-100 protein is a $20-\mathrm{kDa}$ acidic calciumbinding protein, so named for its solubility in $100 \%$ ammonium sulfate. The protein is composed of two subunits, $\alpha$ and $\beta$, which combine to form three isotypes. The $\alpha-\alpha$ isotype is normally found in myocardium, skeletal muscle, and neurons; the $\alpha-\beta$ isotype is present in melanocytes, glia, chondrocytes, and skin adnexa; and the $\beta-\beta$ isotype is seen in Langerhans cells and Schwann cells.

The function of CD34, a $110-\mathrm{kDa}$ transmembrane glycoprotein, is thought to be related to cell-cell adhesion. It is expressed on hematopoietic stem cells, endothelium, the interstitial cells of Cajal, and a group of interesting dendritic cells present in the dermis, around blood vessels, and in the nerve sheath.

\section{METHODS}

This is combined prospective and retrospective observational study conducted in the department of pathology, Gandhi Medical College and Hamidia Hospital Bhopal, Madhya Pradesh from $1^{\text {st }}$ January 2018 to $30^{\text {th }}$ June 2019. The study was approved by ethics committee and informed consent was obtained.

\section{Immunohistochemistry Procedure ${ }^{3}$}

1. Paraffin blocks were placed on ice blocks for few minutes prior to cutting sections.

2. $3-4 \mathrm{~mm}$ thick sections were cut and gently lowered on surface of water bath at $45^{\circ} \mathrm{C}$ and was spread wrinkle free on to the poly L-lysine coated slide.

3. Baking: Slides were further kept on hot plate at $60^{\circ} \mathrm{C}$ for 30 minutes.

4. De-warming and rehydration: Slides were further dipped in Coplin jar containing following. - Xylene-I for 10 minutes. $\bullet$ Xylene-II for 5 minutes. $\bullet$ Absolute alcohol for 2 minutes. • $90 \%$ alcohol for 2 minutes. • $70 \%$ alcohol for 2 minutes.

5. Antigen retrieval in pressure cooker: Slides were placed in pressure cooker containing preheated citrate buffer and boiled for one whistle and further allowed to cool naturally for 20 minutes.

6. Slides were then washed with PBS for 3 times for 3 minutes each.

7. Blocking Endogenous Enzyme: Slides were wiped thoroughly with tissue paper and incubated in ultravision hydrogen peroxide block for 20 minutes in moist chamber at room temperature.

8. Ultra-vision protein block was applied and incubated for 07 minutes to block nonspecific background staining. (NOTE: Should not exceed 10 minutes or there may be reduction in desired stain). 
9. Blow Step. No buffer wash step.

10. Primary Antibody: Primary antibody (vimentin, desmin, $S$ 100, CD34) was added and slides were incubated in moist chamber for 60 minutes.

11. Buffer wash step.

12. Amplification of Primary Antibody: Primary Antibody Amplifier Quanto was added and incubated in moist chamber for 20 minutes followed by buffer wash step.

13. Secondary Antibody: HRP Polymer Quanto was applied and was incubated in moist chamber for 20 minutes.

14. Buffer wash step.

15. Substrate: 30 micro litre / 1 drop dab quanto chromogen was added to $1 \mathrm{ml}$ of DAB Quanto Substrate, mixed by swirling movement was applied to tissue and incubated for 5 minutes.

16. Distilled water wash step.

17. Slides were then counterstained and coverslips were applied onto them using DPX.

\section{Interpretation}

Stained section were examined under microscope and were graded by using a combination of staining intensity and percentage of positive cells. Semi quantitative scoring system (Bondarenko et al, 2014) is claimed to be a good scoring system which assess both the proportion of stained cells and the intensity of staining. By using light microscopy, the relative intensity of staining in each of a given number of the tumour cells was assessed and recorded for each specific IHC marker. The tissues examined under variety of microscopic magnifications. 4 - 40x Magnifications were commonly used in making a final assessment of IHC staining intensities and percentages of stained cells. Heterogeneities in soft tissue malignancies is a common finding (e.g., IHC staining intensities can vary throughout the tumour) and that's why all areas of tumour were evaluated in order to avoid a biased selection of more or less intense staining areas. Thus the number of cells evaluated in each tissue differed depending on the amount of evaluable tissue / cells available. Four intensity levels were used in scoring.

\begin{tabular}{|c|c|c|}
\hline $\begin{array}{c}\text { \% of Immunohistochemical } \\
\text { Labelled Cells } \\
\text { (A) }\end{array}$ & $\begin{array}{l}\text { Intensity of IHC } \\
\text { Reaction } \\
\text { (B) }\end{array}$ & $\begin{array}{c}\text { Final Score } \\
\qquad \mathbf{A}+\mathbf{B}\end{array}$ \\
\hline $0-\quad 0 \%$ & 0 - No Staining & $A+B=$ Range from 0 to 6 \\
\hline $1-<30 \%$ & $1+$ Weak Staining & \\
\hline $2-\quad 30-60 \%$ & $2+$ Moderate Staining & \\
\hline $3-\quad>60 \%$ & $3+$ Strong Staining & \\
\hline \multicolumn{3}{|c|}{ Table 1. Semi Quantitative Scoring System } \\
\hline
\end{tabular}

\section{Statistical Analysis}

The statistical package for social science $\{$ SPSS $\}$ version 20 will be used for data analysis. Mean, median, and SD are used to describe quantitative data. Qualitative data are summarized using frequency and percentage.

\section{RESULTS}

The study included 50 cases of malignant soft tissue tumours (MSTT) during January 2018 to June 2019, received in Department of Pathology at GMC, Bhopal. Most common group encountered in our study was tumour of uncertain differentiation, 17 cases (34\%) followed by fibrohistiocytic group, 8 cases (16\%) out of 50 cases of MSTT. Liposarcoma was the least common entity among our study, only 1 case $(2$ $\%$ ) encountered.

Most of the tumour groups were showing male preponderance with overall $\mathrm{M}$ : $\mathrm{F}$ ratio of 1.08:1. Except tumour of uncertain differentiation and fibroblastic tumours as these were showing female preponderance with $\mathrm{M}$ : F ratio of $0.55: 1$ and $0.75: 1$ respectively.

Second decade was the most common age group affected in our study (probably due to high number of EWS encountered in our study), followed by third and fourth decade as total 11 cases (22.0\%), 09 cases (18.0\%) and 09 cases $(18.0 \%)$ was found in these age groups respectively. In our study lower extremities $46.0 \%$ (23 out of 50) was the most commonly affected site followed by the trunk $32 \%$ (16 out of 50). Grossly most of the tumours were having size $>5$ CM (64\%) in present study.

$\left.\begin{array}{|cccc|}\hline \text { S1. No. } & \text { Tumour } & \begin{array}{c}\text { Total Positive / } \\ \text { Total Cases }\end{array} & \begin{array}{c}\text { IHC Score } \\ \text { 0 to } 6\end{array} \\ 1 . & \text { MFH } & 07 / 08 & 0 \text { to } 6\end{array}\right)$

\begin{tabular}{|c|c|c|c|}
\hline Sl. No. & Tumour & $\begin{array}{l}\text { Total Positive } \\
\text { / Total Cases }\end{array}$ & $\begin{array}{c}\text { Bondarenko Score } \\
\text { (IHC SCORE } 0 \text { - 6) }\end{array}$ \\
\hline 1. & Fibrohistiocytic & $00 / 08$ & 00 \\
\hline 2. & Adipocytic & $00 / 01$ & 00 \\
\hline 3. & Skeletal muscle & $05 / 05$ & 2 to 4 \\
\hline 4. & Smooth muscle & $02 / 02$ & 3 to 4 \\
\hline 5. & Fibroblastic & $00 / 07$ & 00 \\
\hline 6. & Nerve sheath & $00 / 03$ & 00 \\
\hline 7. & $\begin{array}{c}\text { Tumour of uncertain } \\
\text { differentiation } \\
\text { EWS } \\
\text { Synovial sarcoma } \\
\text { SRBCT }\end{array}$ & $\begin{array}{l}00 / 12 \\
00 / 03 \\
00 / 02\end{array}$ & $\begin{array}{l}00 \\
00 \\
00\end{array}$ \\
\hline 8. & GIST & $00 / 05$ & 00 \\
\hline 9. & Undifferentiated & $00 / 02$ & 00 \\
\hline 10. & Total & $07 / 50$ & 0 to 4 \\
\hline
\end{tabular}

Vimentin was showing immunopositivity in 43 out of 50 cases of MSTT. 7 cases were reported negative for vimentin including 4 cases of EWS, 2 cases of SS and 1 case of MFH.

All 5 cases of Rhabdomyosarcoma and 2 cases of Leiomyosarcoma were showing Immunoexpression for Desmin. Rest all of the tumours were negative for Desmin.

All cases of fibroblastic tumours \& GIST were positive for CD 34 apart from these 2 cases of MFH, 1 case of LMS, 2 cases 
of MPNST, 1 case of SRBCT and 1 case of undifferentiated tumours was showing CD 34 positivity.

\begin{tabular}{|c|c|c|c|}
\hline $\begin{array}{l}\text { Sl. } \\
\text { No. }\end{array}$ & Tumours & $\begin{array}{l}\text { Total Positive } \\
\text { / Total Cases }\end{array}$ & $\begin{array}{c}\text { Bondarenko Score } \\
\text { (IHC Score } 0 \text { - 6) }\end{array}$ \\
\hline 1. & Fibrohistiocytic & $02 / 08$ & 00 to 04 \\
\hline 2. & Adipocytic & $00 / 01$ & 00 \\
\hline 3. & Skeletal muscle & $00 / 05$ & 00 \\
\hline 4. & Smooth muscle & $01 / 02$ & 00 to 05 \\
\hline 5. & Nerve sheath & $02 / 03$ & 00 to 04 \\
\hline 6. & Fibroblastic & $07 / 07$ & 2 to 6 \\
\hline 7. & $\begin{array}{c}\text { Tumour of uncertain } \\
\text { differentiation } \\
\text { EWS } \\
\text { Synovial sarcoma } \\
\text { SRBCT }\end{array}$ & $\begin{array}{l}00 / 12 \\
00 / 03 \\
01 / 02\end{array}$ & 00 to 04 \\
\hline 8. & GIST & $05 / 05$ & 02 to 05 \\
\hline 9. & Undifferentiated & $01 / 02$ & 00 to 03 \\
\hline 10. & Total & $19 / 50$ & 0 to 6 \\
\hline \multicolumn{4}{|c|}{ Table 4. CD 34 Immune Expression } \\
\hline
\end{tabular}

$\left.\begin{array}{|cccc|}\hline \text { Sl.No. } & \text { Tumours } & \begin{array}{c}\text { Total Positive / } \\ \text { Total Cases }\end{array} & \begin{array}{c}\text { Bondarenko Score } \\ \text { (IHC Score 0 - 6) }\end{array} \\ \hline 1 . & \text { Fibrohistiocytic } & 05 / 08 & 00 \text { to } 03\end{array}\right)$

All 3 cases of MPNST, both the cases of LMS and the only case of liposarcoma were showing immunopositivity for S 100 . 5 out of 8 cases of MFH, 2 out of 5 cases of RMS and 1 out of 5 cases of GIST were also showing positivity for S 100 .

\section{DISCUSSION}

In the present study, all the fibroblastic tumours were positive for CD34 and vimentin and negative staining for desmin and S100. Hattinger C.M. et al. ${ }^{4}$ (2004) Italy did a research on genetic and immunohistochemical analysis of fibrosarcoma and found out that vimentin was positive in all the 18 cases with negative desmin CD34, S100 and SMA. We found out in our study that vimentin and CD 34 Were positive in all 3 cases of fibrosarcoma with negative desmin and S100.

Abenoza P et al. ${ }^{5}$ 1993, Goldblum JR et al. ${ }^{5}$ 1997, His ED et al. ${ }^{7}$ 2003, Rodney T, Miller et al. ${ }^{8} 2008$ conducted IHC study for CD34 positivity in dermatofibrosarcoma protuberans (DFSP), in which CD34 was positive in $100 \%, 92 \%, 96,100 \%$ respectively. In present study, CD34 positivity in DFSP was 100. Rosenberg AE et al. from Massachusetts, performed an IHC study on 34 cases of malignant fibrous histiocytoma (MFH), in which CD 34 was positive in 20 cases whereas S100 was focally positive. ${ }^{9}$ In our study, 7 out of 8 cases were positive for vimentin, 2 out of 8 were positive for CD34, 5 out of 8 were positive for $\mathrm{S} 100$ and desmin was negative in all the 8 cases.
M. Altmannsberger et al.10 Germany performed a study on 25 cases of rhabdomyosarcoma in which most (95\%) of the tumour cells were desmin positive, indicating a muscle origin and supporting the diagnosis of rhabdomyosarcoma. In our study, 5 cases of rhabdomyosarcoma were encountered, all of them were desmin positive.

A study conducted by Bharat Rekhi et al. ${ }^{11}$ India on liposarcoma, 12 out of 13 were S 100 positive, only a single case was showing negative staining with CD 34 positivity. In the present study only one case of liposarcoma was included which was positive for S 100 and negative for CD 34 .

Liu et al. ${ }^{12}$ revealed that CD34 showed strong positive expressions in gastrointestinal stromal tumours (GISTs), with the positive rates of $92.3 \%$ of the GISTs in that study. Rabin et al. ${ }^{13}$ found $40 \%$ to $70 \%$ of GISTs were positive for CD34, 10 $\%$ were showing positive result for S100 protein and $<5 \%$ were positive for desmin. In our study, all the 5 cases were showing positivity for CD 34 and vimentin, 1 out 5 cases was positive for $\mathrm{S} 100$ and all of them were negative for desmin.

A study conducted by Stasik CJ, Tawfik O et al.,14 on malignant peripheral nerve sheath tumour (MPNST) revealed S-100 positivity in only about $50-90 \%$ of the tumours. In our study, all the 3 cases of MPNST were positive for $\mathrm{S} 100$ and all of them were desmin negative. Bharat Rekhi et al., ${ }^{15}$ India conducted a study on 42 cases of synovial sarcoma, negative for CD34 in all 21 tumours, wherever performed. In our study, all the 3 cases of synovial sarcoma were negative for CD 34 .

Toshifumi Ozaki et al.16 Japan conducted a study on 188 cases of embryonal sarcoma (ES) during 2006 to 2011 were showing positivity for neural markers such as S-100 protein sometimes and vimentin positivity was also commonly observed. In our study 8 out 12 cases were positive for vimentin and desmin, CD 34 and S100 were negative in all the 12 cases. A study conducted by Ceballos KM, Nielsen GP, Selig MK, O'Connell JX et al. 2000 revealed, leiomyosarcomas were expressed with vimentin and desmin in the majority of the cases. Some co-express S100 protein. ${ }^{17}$ In our study, 2 cases of leiomyosarcoma were encountered. Desmin, vimentin and $\mathrm{S}$ 100 were positive in both the cases. 1 out of 2 cases was CD 34 positive.

Changhua Wu, Liang Wang et al. ${ }^{18}$ China, 2019 conducted a study on undifferentiated soft tissue sarcomas. In which it was found vimentin positivity and weak ki-67 positivity were seen, consistent with the diagnosis of high-grade, undifferentiated embryonal sarcoma. Immunohistochemistry (IHC) did not show myogenin and myoD1 positivity, making rhabdomyosarcoma unlikely. The tumour cells were negative for SMA, desmin, S-100, CD34, CD99, and CK. In present study, 3 cases of undifferentiated soft tissue sarcomas were included, vimentin was positive in all the 2 cases, 1 out 2 was positive for CD 34. All of them were negative for Desmin and S 100 .

\section{CONCLUSIONS}

Most common MSTT was tumour of uncertain differentiation $34.0 \%$ followed by fibrohistiocytic tumour $16.0 \%$ and fibroblastic $14.0 \%$. IHC markers CD 34 and vimentin were of great significance in distinguishing between various fibroblastic tumours and hence confirming the diagnosis. S100 positivity helped in making diagnosis of MPNST and lipomatous lesions. Desmin showed positivity in 
rhabdomyosarcomas and leiomyosarcomas only. CD 34 negativity was further confirmed in synovial sarcomas. IHC was supporting histopathological diagnosis in 48 / 50 cases and helped in making diagnosis of 02 / 50 cases (in which histopathology was giving equivocal results). Immunohistochemistry with cytogenetics for a large number of malignant soft tissue cases are advised in future which may provide results of prognostic significance.

Data sharing statement provided by the authors is available with the full text of this article at jemds.com.

Financial or other competing interests: None.

Disclosure forms provided by the authors are available with the full text of this article at jemds.com.

\section{REFERENCES}

[1] Brooks JS. Immunohistochemistry in the differential diagnosis of soft tissue tumours. Monogr Pathol 1996;38:65-128.

[2] Fletcher CD. The evolving classification of soft tissue tumours: an update based on the new WHO classification. Histopathology 2006;48(1):3-12.

[3] Layton C, Bancroft JD. The hematoxylins and eosin and immunohistochemical techniques. In: Suvarna KS, Layton C, Bancroft JD. Bancroft's theory and practice of histological techniques. $7^{\text {th }}$ edn. Churchill Livingstone 2012:173-86.

[4] Hattinger CM, Tarkkarnen M, Benini S, et al. Genetic and immunohistochemical analysis of fibrosarcoma of soft tissue, a rare tumour entity closely related to malignant fibrous histiocytoma. European Journal of Cell Biology 2004;83(9):483-91.

[5] Abenoza P, Lillemoe T. CD 34 and factor XIIIa in the differential diagnosis of dermatofibroma and dermatofibrosarcoma protuberans. Am J Dermatopathol 1993;15(5):429-34.

[6] Goldblum JR, Tuthill RJ. CD34 and factor-XIIIa immunoreactivity in dermatofibrosarcoma protuberans and dermatofibroma. Am J Dermatopathol 1997;19(2):147-53.
[7] His ED, Nickoloff BJ. Dermatofibroma and dermatofibrosarcoma protuberans: an immnunohistochemical study reveals distinctive antigenic profiles. J Dermatol Sci 1996;11(1):1-9.

[8] Miller RT. Immunohistochemistry in dermatofibrosarcoma protuberans vs dermatofibromafibrous histiocytoma. Histopathology 2006;48:3-12.

[9] Rosenberg AE, O'Connell JX, Dickersin GR, et al. Expression of epithelial markers in malingnant fibrous histiocytoma of the musculoskeletal system: an immunohistochemical and electron microscopic study. Hum Pathol 1993;24(3):284-93.

[10] Altmannsberger M, Weber K, Droste R, et al. Desmin is a specific marker for rhabdomyosarcomas of human and rat origin. Am J Pathol 1985;118(1):85-95.

[11] Rekhi B, Navale P, Jambhekar NA. Critical histopathological analysis of 25 dedifferentiated liposarcomas, including uncommon variants, reviewed at a tertiary cancer referral center. Indian J Pathol Microbiol 2012;55(3):294-302.

[12] Liu FY, Qi JP, Xu FL, et al. Clinicopathological and immunohistochemical analysis of gastrointestinal stromal tumor. World J Gastroenterol 2006;12(26):41615.

[13] Rabin I, Chikman B, Lavy R, et al. Gastrointestinal stromal tumuors: a 19 year experience. Isr Med Assoc J 2009;11(2):98-102.

[14] Stasik CJ, Tawfik O. Malignant peripheral nerve sheath tumor with rhabdomyosarcomatous differentiation (Malignant Triton Tumor). Arch Pathol Lab Med 2006;130(12):1878-81.

[15] Rekhi B, Basak R, Desai SA, et al. Immunohistochemical validation of TLE1, a novel marker, for synovial sarcomas. Indian J Med Res 2012;136(5):766-75.

[16] Ozaki T. Diagnosis and treatment of Ewing sarcoma of the bone: a review article. J Orthop Sci 2015;20(2):250-63.

[17] Ceballos KM, Nielsen GP, Selig MK, et al. Is anti-hcaldesmon useful for distinguishing smooth muscle and myofibroblastictumuors? An immunohistochemical study. Am J Clin Pathol 2000;114(5):746-53.

[18] Wu C, Wang L, Guo L, et al. Undifferentiated sarcoma of the soft tissues with cystic degeneration: case report and review of literature. J Cancer Res Ther 2019;15(4):94752. 